\title{
Construction of eukaryotic surface display based on the baculoviral $F$ protein
}

\author{
Haitao Mao ${ }^{1,2}$, Jianhua Song1, Changyong Liang1, Zehua Yu², and \\ Xinwen Chen ${ }^{1}$ \\ ${ }^{1}$ Chinese Academy of Sciences, Wuhan, and ${ }^{2}$ Central China Normal University, \\ Wuhan, People's Republic of China
}

BioTechniques 41:266-272 (September 2006) doi $10.2144 / 000112237$

The display of foreign proteins on the surface of viruses or cells provides a tool for the analysis and design of biomolecules and their interactions. Phage display of foreign proteins has been an established technology for over a decade, but since it is a prokaryotic expression system, there are limitations (e.g., in glycosylation and the folding of complex proteins). Eukaryotic display, such as baculovirus display, makes the expression of these complex, glycosylated proteins possible (1-6). The potential of baculovirus display for the generation and screening of a eukaryotic expression library (7) or for the production of monoclonal antibodies (8) has also been demonstrated.

Two distinct envelope fusion proteins are identified in baculovirus budded virions (BV). GP64 is the major envelope fusion protein of group I nucleopolyhedrovirus (NPV) BVs, which mediates low pH-triggered membrane fusion (9) and is necessary for efficient budding of BVs from the surface of infected cells (10). An unrelated but functionally analogous type of envelope fusion protein, named $\mathrm{F}$, is encoded by group II NPVs, such as Spodoptera exigua multiple-embedded NPV (SeMNPV) and Lymantria dispar MNPV (LdMNPV) $(11,12)$. Like GP64 homologous proteins, F proteins mediate low $\mathrm{pH}$-dependent membrane fusion during BV entry $(12,13)$. The open reading frame (ORF) 133 (Ha133) of Helicoverpa armigera single nucleocapsid NPV (HearNPV) encodes an $\mathrm{F}$ protein that is posttranslationally cleaved, and the two cleavage fragments-the $59 \mathrm{kDa}$ transmembrane anchored $F_{1}$ and the $20 \mathrm{kDa} \mathrm{F}_{2}$, which remain associated by a disulfide bridge-are responsible for virus entry into the host cells and efficient virion budding (14). For display, it is sufficient to fuse the heterologous peptide to the $\mathrm{N}$ terminus of gp64 or to the gp64 transmembrane domain (1-5). In this report, we describe the successful development of an alternative eukaryotic display system based on the $\mathrm{F}$ protein of HearNPV.

A novel surface display system with HearNPV was developed using the hal33 gene encoding the surface glycoprotein $\mathrm{F}$ (or Ha133) by using the HearNPV Bac-to-Bac ${ }^{\circledR}$ system (Invitrogen, Carlsbad, CA, USA). Several donor plasmids were generated for insertion of genes into the HearNPV bacmid (HaBacHZ8) by Tn7-mediated transposition (15). All donor plasmids contain a green fluorescent protein (GFP) reporter gene under the control of the $p 10$ promoter and an $f$-gst fusion gene with the 183-bp HearNPV ha133 promoter. According to the main functional domains of Ha133 (14), we chose two sites for insertion of the marker gene glutathione S-transferase (GST): one site between the signal peptide and the mature protein, and the other between the $\mathrm{F}_{1}$ and $\mathrm{F}_{2}$ domains.
To get the fusion fragment of $g s t$ and $f$ genes, we synthesized the $f$ gene (or ha133) into four fragments (Ha1331, Ha133-2, Ha133-3, and Ha133-4) by PCR with HearNPV G4 genomic DNA as template. The Ha133-1 fragment, including the 183-bp ha133 promoter and the signal peptide [1-29 amino acids (aa)], was amplified with primers surf-1 and surf-2 (Table 1). The Ha133-2 fragment containing the $F_{1}\left(174-677\right.$ aa) and $F_{2}(30-173$ aa) domains of Ha133 was amplified with primers surf- 3 and surf- 4 (Table 1). The Ha133-3 fragment, including the 183-bp hal33 promoter, the signal peptide (1-29 aa), and the $\mathrm{F}_{2}$ domain (30-147 aa) of Ha133, was amplified with primers surf- 1 and surf-5 (Table 1). The Ha133-4 fragment, which is the $\mathrm{F}_{1}$ domain (148-677 aa) of Ha133, was amplified with primers surf- 6 and surf4 (Table 1). The GST gene was obtained by PCR from plasmid pGEX-3X with primers GF and GR (Table 1). All PCR products were cloned into pGEM $^{\circledR}{ }_{-} \mathrm{T}$ Easy vector (Promega, Madison, WI, USA) and verified by sequencing.

The fragments Ha133-1, GST, and Ha133-2 were inserted into pFast ${ }^{\mathrm{TM}} \mathrm{Bac} 1$ (Invitrogen) and produced the plasmid pFBI-GSTHaF-I. Another plasmid pFBI-GSTHaF-II was constructed in same method by insertion of the fragments (Ha133-3, GST, and Ha1334) into pFastBac1. Then the GST-HaF fusion cassette from the plasmid pFBIGSTHaF-I and pFBI-GSTHaF-II as a BamHI (blunt)-HindIII fragment was subcloned into the Bst1107I (blunt) and HindIII sites of pFBDeGFP and produced two recombinant donor

Table 1. Primers Used in This Study

\begin{tabular}{|llc|}
\hline Primer & Sequence & $\begin{array}{c}\text { Restriction } \\
\text { Enzymes }\end{array}$ \\
\hline surf-1 & 5'-GCGGATCCATAACCTCTAAAATGTGTAATCC-3' & BamHI \\
surf-2 & 5'-GCGAATTCTCGCGTCAACGACATAGA-3' & EcoRI \\
surf-3 & 5'-CGGCTGCAGGTCGTCGAAACGACAGAG-3' & Pstl \\
surf-4 & 5'-GGCAAGCTTTACAATTTGTGTTCATCATAT-3' & Hindll \\
surf-5 & 5'-GCGAATTCTAAGTCGGGATTCATTGC-3' & EcoRI \\
surf-6 & 5'-CGGCTGCAGGTACAAATCGATGCTAACC-3' & $P s t l$ \\
GF & 5'-CGGAATTCATGTCCCCTATACTAGGTTATTG-3' & EcoRI \\
GR & 5'-GGCCTGCAGTTTTGGAGGATGGTCGC-3' & $P s t l$ \\
Underlined and bolded nucleotides indicate restriction enzyme sites and a translation stop codon, \\
respectively.
\end{tabular}




\section{Benchmarks}
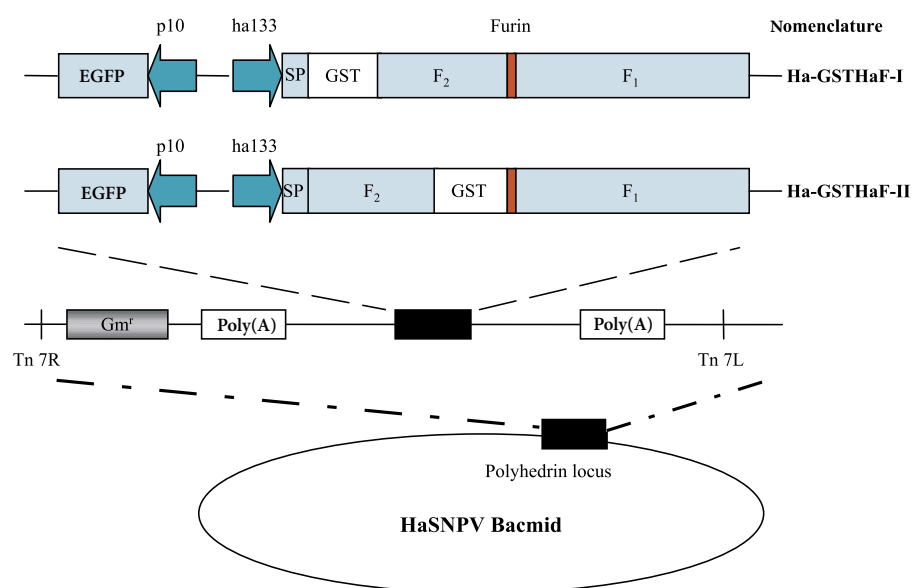

Figure 1. Recombinant bacmid constructs, showing the strategy for insertion of the gene cassettes into the polyhedrin locus of the HearNPV bacmid. Glutathione S-transferase (GST) was fused with HearNPV $F$ protein either between the signal peptide (SP) and the $F_{2}$ domain or just before the furinlike cellular convertase site (Furin). Both cassettes depicted were inserted into the attb site (indicated by right and left insertion sites, Tn7R and Tn7L) in the polyhedrin locus by a Tn-based transposon. EGFP, enhanced green fluorescent protein.

plasmids pFBDeGFP-GSTHaF-I and pFBDeGFP-GSTHaF-II, respectively. pFBDeGFP was a derivate of pFastBacDual (Invitrogen) by inserting the coding sequence for enhanced GFP (EGPF) as a SmaI-KpnI fragment downstream of the p10 promoter. The two final donor plasmids mediated insertion of genes into the HearNPV bacmid by Tn7-mediated transposition to generate the bacmids Ha-GSTHaFI and Ha-GSTHaF-II, respectively (Figure 1).

HzAM1 cells were transfected with Ha-GSTHaF-I and Ha-GSTHaF-II DNA and detected GFP-expression signal at 3 days posttransfection. The supernatant from Ha-GSTHaF-I transfectional Hz-AM1 could infect and amplify in Hz-AM1 cells. However, no GFP signal was detected in the cells treated with the transfectional supernatant of Ha-GSTHaF-II even after multiple attempts. The result indicates that the Ha-GSTHaF-II bacmid could not generate an infectious virus. This might be due to the GST fusion at the $\mathrm{C}$ terminal of the $\mathrm{F}_{2}$ domain interfering with the disulfide bridge between the $\mathrm{F}_{2}$ and $\mathrm{F}_{1}$ domain, which is responsible for virus entry into the host cells and efficient virion budding. The infectivity of Ha-GSTHaF-I was further analyzed. The titer of Ha-GSTHaF-I was $1.2( \pm 0.24) \times 10^{7}$ plaque-forming units $(\mathrm{pfu}) / \mathrm{mL}$, which was similar to the wild-type virus $\left[1.3( \pm 0.08) \times 10^{7}\right.$ $\mathrm{pfu} / \mathrm{mL}$ ], and was stable in subsequent passages (data not shown). These results indicated that the insertion, which is in the site between the signal peptide and the mature protein, did not disturb virus propagation.

To determine whether the GST-HaF chimeric protein was incorporated into non-occluded virus particles, budded virions were harvested from infected cell cultures by centrifugation through a sucrose cushion. The samples obtained were analyzed by Western blot analysis (Figure 2). Labeling with an anti- $\mathrm{HaF}_{2}$ serum antibody $\left(\alpha-\mathrm{HaF}_{2}\right)$ directed against the $\mathrm{Ha} 133 \mathrm{~F}_{2}$ fragment showed a protein of approximately $20 \mathrm{kDa}$ in both vHa-GSTHaF-I and wild-type virus, representing the $\mathrm{Ha}_{13} 3 \mathrm{~F}_{2}$ protein (Figure $2 \mathrm{~A})$. In the vHa-GSTHaF-I budded viruses, another protein of about $47 \mathrm{kDa}$ was present, which was also recognized by an anti-GST serum antibody ( $\alpha$-GST) (Figure 2B), representing the GST- $\mathrm{F}_{2}$ fragment, which was the $\mathrm{N}$-terminal of the fusion protein after being cleaved by furin. The wild-type HearNPV also showed an additional band of approximately $80 \mathrm{kDa}$, representing the intact $\mathrm{F}$ protein (Ha133), which is not cleaved as in previous reports (15).

Immunofluoresence staining was performed in HzAM1 cells infected with vHa-GSTHaF-I. With a specific antiGST serum antibody and with a second antibody conjugated to rhodanmine $\mathrm{B}$, a strong red peripheral fluorescence was observed, which surrounded the cytoplasm and was located on the cell membrane (Figure 2C). In cells infected with the control G4 (wild-type HearNPV), we could not observe any red fluorescence in the cells or on their surface (data not shown). This indicated that the fusion protein was present on the membrane of infected cells.

HearNPV is a major pathogen of the cotton bollworm and has been widely used as pesticide to control the host in China. The ability of HearNPV to display F-GST fusion proteins offers the possibility of using this baculovirus as a vector for the production and display of target proteins on the viral surface. The purified virus particles displaying the cloned foreign protein on the viral envelope could be used directly for interaction studies without isolating the proteins.

\section{ACKNOWLEDGMENTS}

This paper is dedicated to the memory of Zehua Yu, who died of cancer last year. We are grateful to Dr. Simon Rayner for a critical review of the manuscript. This work was supported by National Basic Research Priorities Program of China (2003CB1140) and National Nature Science Foundations of China (30325002, 30470075).

\section{COMPETING INTERESTS STATEMENTS}

The authors declare no competing interests.

\section{REFERENCES}

1. Boublik, Y., P. Di Bonito, and I.M. Jones. 1995. Eukaryotic virus display: engineering the major surface glycoprotein of the Autographa californica nuclear polyhedrosis virus (AcNPV) for the presentation of foreign proteins on the virus surface. Biotechnology (NY) 13:1079-1084.

2. Grabherr, R., W. Ernst, O. DoblhoffDier, M. Sara, and H. Katinger. 1997. Expression of foreign proteins on the surface of Autographa californica nuclear polyhedrosis virus. BioTechniques 22:730-735.

3. Rahman, M.M. and K.P. Gopinathan. 2003. Bombyx mori nucleopolyhedrovirusbased surface display system for recombinant proteins. J. Gen. Virol. 84:2023-2031.

4. Raty, J.K., K.J. Airenne, A.T. Marttila, V. Marjomaki, V.P. Hytonen, P. Lehtolainen, O.H. Laitinen, A.J. Mahonen, et al. 2004 


\section{Benchmarks}

Enhanced gene delivery by avidin-displaying baculovirus. Mol. Ther. 9:282-291.

5.Oker-Blom, C., K.J. Airenne, and R. Grabherr. 2003. Baculovirus display strategies: Emerging tools for eukaryotic libraries and gene delivery. Brief Funct. Genomic Proteomic 2:244-253.

6. Rahman, M.M., M.S. Shaila, and K.P. Gopinathan. 2003. Baculovirus display of fusion protein of Peste des petits ruminants virus and hemagglutination protein of Rinderpest virus and immunogenicity of the displayed proteins in mouse model. Virology 317:36-49.

7. Ernst, W., R. Grabherr, D. Wegner, N. Borth, A. Grassauer, and $H$. Katinger. 1998. Baculovirus surface display: construction and screening of a eukaryotic epitope library. Nucleic Acids Res. 26:1718-1723.

8. Lindley, K.M., J.L. Su, P.K. Hodges, G.B. Wisely, R.K. Bledsoe, J.P. Condreay, D.A. Winegar, J.T. Hutchins, and T.A. Kost. 2000. Production of monoclonal antibodies using recombinant baculovirus displaying gp64-fusion proteins. J. Immunol. Methods 234:123-135.

9. Blissard, G.W. and J.R. Wenz. 1992. Baculovirus gp64 envelope glycoprotein is sufficient to mediate $\mathrm{pH}$-dependent membrane fusion. J. Virol. 66:6829-6835.

10. Oomens, A.G. and G.W. Blissard. 1999. Requirement for GP64 to drive efficient budding of Autographa californica multicapsid nucleopolyhedrovirus. Virology 254:297314.

11.IJkel, W.F., M. Westenberg, R.W. Goldbach, G.W. Blissard, J.M. Vlak, and D. Zuidema. 2000. A novel baculovirus envelope fusion protein with a proprotein convertase cleavage site. Virology 275:30-41.

12.Pearson, M.N., R.L. Russell, and G.F. Rohrmann. 2001. Characterization of a baculovirus-encoded protein that is associated with infected-cell membranes and budded virions. Virology 291:22-31.

13. Westenberg, M., H. Wang, I.J. WF, R.W. Goldbach, J.M. Vlak, and D. Zuidema. 2002. Furin is involved in baculovirus envelope fusion protein activation. J. Gen. Virol. 76:178-184.

14. Long, G., M. Westenberg, H. Wang, J.M. Vlak, and Z. Hu. 2006. Function, oligomerization and N-linked glycosylation of the Helicoverpa armigera single nucleopolyhedrovirus envelope fusion protein. J. Gen. Virol. 87:839-846.

15. Wang, H., F. Deng, G.P. Pijlman, X. Chen, X. Sun, J.M. Vlak, and Z. Hu. 2003. Cloning of biologically active genomes from a Helicoverpa armigera single-nucleocapsid nucleopolyhedrovirus isolate by using a bacterial artificial chromosome. Virus Res. 97:57-63.

Received 2 May 2006; accepted 16 June 2006.

Address correspondence to Xinwen Chen, State Key Laboratory of Virology, Wuhan Institute of Virology, Chinese Academy of Sciences, Wuhan 430071, People's Republic of China. e-mail: chenxw@pentium.whiov.ac.cn

\section{A}

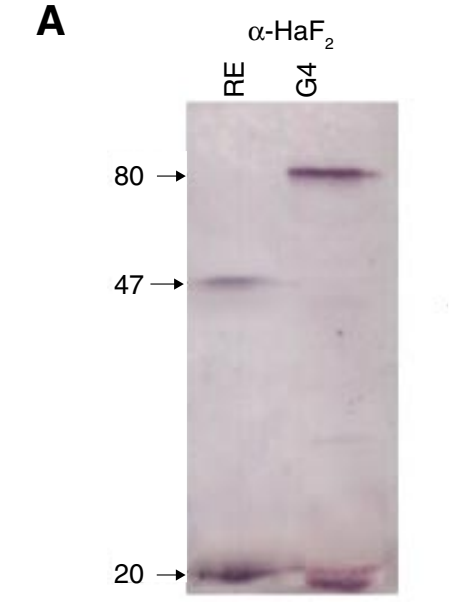

B $\alpha-G S T$ C $\alpha$-GST
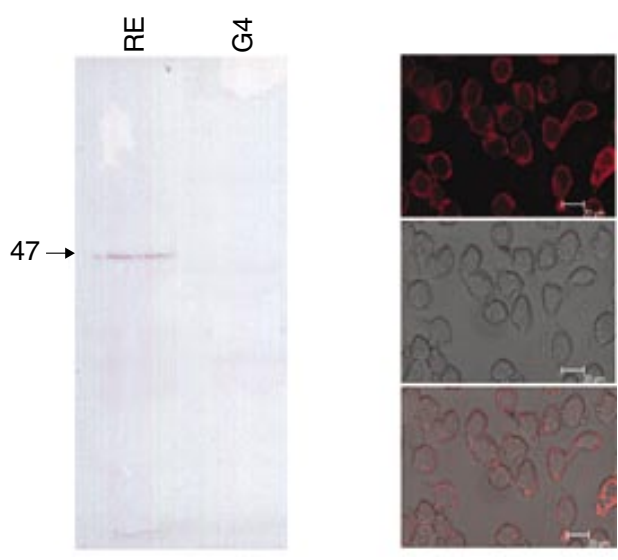

Figure 2. F-GST fusion protein expression detection in HearNPV budded virions and infected HzAM1 cells. (A and B) Western blot analysis of HearNPV recombinant baculovirus budded virions (BV). BVs were harvested from cells infected with either wild-type HearNPV G4 (G4) or vHa-GSTHaF-I (RE) and subjected to sodium dodecyl sulfate polyacrylamide gel electrophoresis (SDS-PAGE) followed by Western blot analysis with (A) anti- $\mathrm{HaF}_{2}$ serum $\left(\alpha-\mathrm{HaF}_{2}\right)$ and $(\mathrm{B})$ anti-GST serum $(\alpha-\mathrm{GST})$. (C) Immunoblot analysis of F-GST expression in infected Hz-AM1 cells by using an anti-GST antibody. HzAM1 was infected with vHa-GSTHaF-I at multiplicity of infection (MOI) of 10 and was examined under a confocal microscope. GST, glutathione S-transferase. 